\title{
Stop wasting! A plea for maintenance
}

\author{
Felicia Veronica Banciu $^{1, *}$, Eugen Pămîntaş ${ }^{1}$ \\ ${ }^{1}$ IMF Department, Mechanical Faculty, Politehnica University of Timişoara, Bd. Mihai Viteazu No. \\ 1, 300222, Timişoara, Romania
}

\begin{abstract}
It is produced, it is worn out, it is thrown away, it is becoming more and more polluted, it is recovering, but it is not completely away, and therefore the material reserves are diminished and some have become even deficient. The handiest solution, at least to slow down the dynamics of pollution and draining of supplies of materials and materials is maintenance. In the following we will explore this solution to make it as efficient and available as possible in industrial application.
\end{abstract}

\section{Clarification Concepts}

We are surrounded by products, of all kinds, tangible and intangible, made by man to cover various needs and which, like everything on earth, suffer physical and moral degradation of functions and characteristics.

To clarify the concepts (notions), the United Nations' International Standard Industrial Classification standard, the Statistical Classification of Economic Activities in the European Community (NACE) in the EU and similar systems elsewhere, have a first-level hierarchy that reflects whether the economic goods are tangible or intangible.

When the product no longer meets the needs or no longer fulfils its functions, it is considered to have ended its so-called life cycle. The specialized literature records dozens of graphic representations of the "product life cycle", some more detailed, others more brief and to make us understand but without entering into controversies with other authors, is presented in figure 1 our own short version, which has basically an analogy with the "life cycle" of a living thing on Earth. The essence of the requirements regardless of the system adopted for the representation and operation of the life cycle of a product, service, etc. is a good design and easy maintenance. These have been and will remain ideal goals, but in some cases achievable. In this paper, we mainly consider the products resulting from a manufacturing process.

In manufacturing (secondary sector), products are bought as raw materials (primary sector) and then sold as finished goods. A service (not as tertiary sector, but with reference to maintenance and service for manufactured products - authors' note) are also regarded to as a type of product [1]. "It is sometimes hard to define whether a given company is part and parcel of the secondary or tertiary sector [2].

The term of circular economy is often met - where the lifecycle of products is extended to reduce the use of raw materials and the production of waste through recycling

\footnotetext{
${ }^{*}$ Corresponding author: felicia.banciu@upt.ro
} 
of what can be recycled in order to reinsert these raw materials at the beginning of this new, endless cycle.

However, with dramatic cost reduction and speed and reliability improvements in the transportation of people and the communication of information, the maintenance sector now includes some of the most intensive international competition.

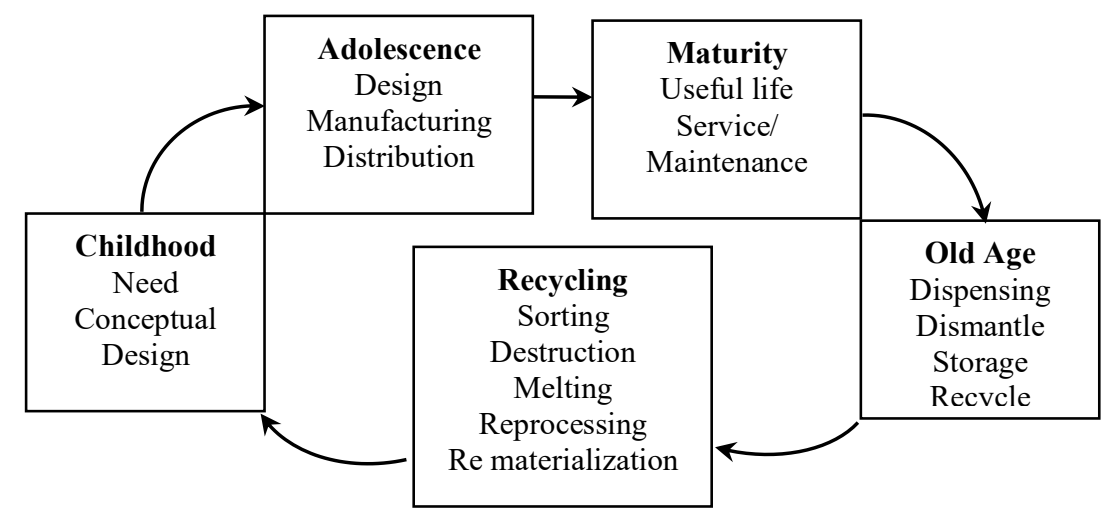

Fig. 1. A vision of product life cycle.

\section{About the manufactured product}

Making a product requires determining the needs or requirements of customers, developing the product concept as a result of the marketing study, developing the technical specifications of the product, product design and manufacturing technologies, the actual manufacturing, distribution and service in warranty and post -guarantee for the products sold, and finally the elimination of the product.

From the above we can only refer to two notions:

a) The notion of service - it must be specified that, on the one hand in this case, the term refers to a tangible product, result of a manufacturing process, and on the other hand, that it in its content includes not only the activities of maintenance organized by the manufacturer for that product but also those that must be performed by the user in order to maintain its operating characteristics.

b) The notion of disposal of the product at the end of the life cycle - we believe that, closer to the reality of the content, would be the use of the terms of withdrawal of the product that has become useless and the recovery of the materials from which it is made. This is because the product cannot be disposed of, literally, i.e. after the removal action there are no traces and no consequences, as if it did not exist. In addition, the result of elimination is at least devoid of positive economic effects, while the reintroduction of recovered materials into the economic circuit is undoubtedly profitable both for the industrial field and for the terrestrial ecosystem.

Recycling and disposal activities provide information on components, materials and other resources, but also on product maintenance, repair and dismissal support systems. A PLM environment enables collaboration between - and informed decision making by various stakeholders of a product over its lifecycle [3]

To see the interest in minimizing waste and facilitating product maintenance, let's briefly review the phase theory of a product design process [4]

- The first phase is to clarify the task (clarification and planning of tasks). The result of this phase is the initial description of the product expressed in the form of a list of functions and features that must be fulfilled by the product, a set of constraints and possibly objectives related to cost and time to market. 
- The conceptual design phase (conceptual study) is seen as an iterative, evolutionary and top-down process, which ultimately leads to a solution of principle or a concept for a product..

- In the embodiment design phase,

-In the last phase, detailed design (detailed conception) are elaborated all the documents regarding the production. All aspects of ergonomics, safety, assembly, operation, maintenance, recycling, costs, aspects that are progressively discovered and suffer from iterations must be taken into account.

Even if the lists of requirements for the future product require the importance of maintenance, it is usually defined briefly, incompletely, insisting only that it should be easy, which in fact has other implications materialized in design rules for carrying out inspection, service and repair - maintenance such as: prefer self-balancing and selfadjusting solutions; aim at simplicity and few parts; use standard components, allow easy access, provide for easy disassembly; apply modular principles, use few and similar service and inspection tools.

At a simple analysis of these rules we find that ensuring easy access is a requirement imposed by ergonomics, ensuring a good view of the defective area, locations for service, inspection, repair must be easily accessible, the tools used must be ergonomic, the location of the defect must be done easily, the change of components must be done easily and last but not least to have clear instructions, procedures and support activities.

\section{About maintenance}

In a very broad sense, maintenance means all the operations of organization, planning, supervision and monitoring of useful functions operation, maintenance, reconditioning and repair by which a product - equipment, machinery or building - is maintained throughout its life cycle so that it operates within the designed parameters.

For practitioners, maintenance means any activities such as inspections, tests, measurements, replacements, adjustments. An enterprise maintenance service may also be determined to participate in studies to improve the industrial process and must take into account numerous restrictions such as quality, safety, environment, costs, etc. According to the European standard EN 13306: 2001, maintenance is the set of all technical, administrative and management actions, during the life cycle of an equipment / system, designed to maintain or restore it in a state in which it can fulfil its required function [5].

NATO's AAP-6 Standardization Agency, in a Glossary of Terms and Definitions [6] provides a broad definition: "Maintenance is the set of measures taken to put or restore a system / equipment to a specified state, until the end of its use, including inspection, testing, maintenance, modification, repair, restoration, reconditioning, reuse, recovery and removal of parts from products to repair other damaged equipment and machinery."

Theorists in the field distinguish several possible types of maintenance: corrective, palliative, systematic preventive, conditional preventive, preventive-planned, predictive, total productive (TPM, which, once chosen, decisively make their mark on a company. Qualitative and quantitative assessment of maintenance is done through a series of indicators, such as: maintainability, average repair time (MTR), average operating times (MTF), failure rate, etc. and also by the volume of maintenance costs.

Maintenance costs include the costs involved in the operation of the maintenance department, which cover the costs of: labor, subcontracting to third parties, spare parts and consumables, equipment and tools, transport and storage of spare parts, reconstruction, automation and self-equipment, training and staff training, etc. Equally significant but more difficult to quantify are the costs of maintenance inefficiency which include: serious personal injury to staff due to insecurity, unavailability of equipment, and the cost of 
replacement measures taken, contractual penalties, intermediate stocks of surplus equipment, non-quality attributable to maintenance non-compliant products, reprocessing, scrap, reclassification of non-compliant products, returns, etc.).

Maintenance activities use a series of methods and tools for: identifying potential product defects (FMEA), developing the most appropriate maintenance strategy in terms of efficiency and costs (RCM - Reliability Centred Maintenance, for which the MIL- STD2173 [7] provides a guide for RCM analysis), analysis of the chain of defects (Analysis of the fault tree - see standard SR EN 61025: 2007), rapid restoration of the operating condition of the product (Maintenance Manual - e.g. British Standard BS EN 13460: 2002 [8], analysis adapted to assess the complex structures of systems and complex maintenance and repair strategies (Markov Analysis).

Maintenance is an important part of life cycle management, its main purpose being to increase the eco-efficiency of the product life cycle [9], [10]. In this sense it aligns with the desideratum that The goal of manufacturing is no longer to produce products in an efficient way, but rather to provide the functions needed by society while minimizing material and energy consumption in order to make our society sustainable through reducing the level of pollution and depletion of materials and energy, maintaining an ecological balance [11].

Also proper maintenance is essential to reduce energy losses. Energy saving through maintenance can be obtained by housekeeping and simple maintenance; condition based maintenance and advanced condition monitoring. [12]. The general rule is to reduce the possibility of failure and failure of products / equipment, reduce maintenance and eliminate it if possible. In other words, instead of analysing the potential failures of the systems, solutions should be analysed for products / equipment that require minimal, inexpensive maintenance and that are easy to repair when they fall.

Several maintainability prediction procedures have been developed, the goal being, instead of predicting how the system will fail, to make products that require minimal maintenance and are easy and inexpensive to fix when they fail [13]. System failure is inevitable at some point, no matter how reliable it is designed to be, it is therefore important to make sure the machine can be quickly restored. Maintainability is an important aspect in overall system continuous improvements efforts, along with reliability, safety, and other factors vital to overall product viability. In fact, many times the term RAMS (Reliability, Availability, Maintainability and Safety) or "reliability and maintainability" will be used [14].

\section{About waste}

Regarding the consumption of industrial products in Europe [15] it is stated that there is an increase in demand and corresponding supply of products so that the use of raw materials and waste production increases. The effects on the environment are obvious. Products and systems are becoming more complex, environmental restrictions, resources that are not inexhaustible, product recycling and ensuring a sustainable design are elements without which products can no longer be manufactured. Specialized knowledge and multidisciplinary teams are needed and the concept no longer exists without the EcoDesign side.

Recent initiatives include reducing pollution, waste management, and protecting the environment. These initiatives should not be seen as solutions negative effects already done, but there should be preventive actions to remove or limit the negative effects on the environment. Thus, all actions regarding the life cycle of a product must be treated in an integrated manner not only from a technical point of view but also integrated from an environmental point of view - which is done with the help of ECoDEsign and Design for sustainability. Each of the stages of the life cycle has an impact on the environment: raw 
materials, manufacturing, distribution, and disposal. The impact can be more or less significant in the long or short term and can occur at regional / local or global level [16].

Here are some of the best known ways to reduce environmental impact [17]:

- Waste reduction: reducing material use through better utilization and by reducing waste during production involves a design with the possibility of extended durability - this being seen as an aspect of quality, involving a decrease in product weight, so that the environment means a decrease in the volume, storage and transport capacity required.

- Materials management: materials recovery, their reuse (recovery must be done considering minimizing all processes related to energy consumption), recycling materials by reusing or reprocessing production waste, products and parts of products, substituting materials for those becoming rare and expensive

- Management of toxic materials:

Pre-processing and reconditioning make significant contributions to effective recycling. Reuse involves retaining the product shape whenever possible. This type of recycling represents a high level of utilization and should therefore be aimed for. Determining the recycling strategy, i.e. if the product or materials from which it is made is recycled, must be the one that will dictate the entire design process.

\section{Conclusions}

If we reduce the maintenance activity strictly to the interventions to keep the product in working order, it would be reduced to having access / being able to disassemble / repairrecondition-replace / reassemble-test. However, its direct dependence on the way in which the product is constructively thought leads to aspects related to the whole process, from the constructive concept to assembly and disassembly and further to reuse and recycling. At the same time, through its involvement in the possibility of repairing / reconditioning certain parts / modules and even products themselves, maintenance is important in terms of ensuring a design for the environment by extending the life of products, reducing costs and reducing the waste of raw materials, materials and energy.

It should be noted that in all the theoretical description of the design process of a product, in no phase is attention drawn to the need to give it other attributes, such as; repairability, accessibility to troubleshooting, disassembly in order to reuse components or selective recycling. Moreover, the notion of maintenance appears only in the last phase, which will cause delays in the process if there are changes to be made to the final project.

But who uses all the theoretical concepts and prescriptions in the current design of new products? An overview of the new products that have appeared on the market in the last decade reveals that they are increasingly "boxed" in terms of not only the functions but also the actual construction. Most of the new products are either irreparable or usually not removable, forcing the user, in case of failure of one of the functions of the product, to dispense with the entire product. The predominant use of non-removable joints or cast metal or composite materials and injected plastics that have inserts of various metallic or non-metallic materials makes it impossible to disassemble for reconditioning or repair and particularly difficult, or economically inefficient, the effort to separate materials for recovery and reuse. In order to avoid the above cases, at least one new rule should be introduced in the design of new products, namely, the priority use of removable joints based on the classic screw-nut and intelligent coupling devices, coupling based, for example, on materials used elastic characteristics.

On the other hand, the challenges posed by changes in the labor market must be taken into account, where, among other things, the lack of qualified staff for various occupations is already a serious threat and even more so in the field of maintenance where the specific 
job of the maintenance operator requires as he knows from all technical branches and therefore are perfectly difficult to train and practical experience is a very important factor.

Engineering faculties must train designers with both an open mind and practical skills for repair and reuse. The product design activity must be done with maintenance in mind both as a design / conception requirement and as an objective to be achieved. Good design and easy maintenance help, on the one hand, to make a product last longer, and on the other hand, it makes it easier to disassemble and sort materials in order to repair, recondition, reuse and finally recycle materials, minimizing both the efforts and the costs and especially the waste of any kind from the resources of humanity-Terra.

\section{References}

1. P. Kotler, G. Armstrong, L. Brown, and S. Adam. Marketing, 7th Ed. Pearson Education Australia/Prentice Hall, (2006)

2. Definition by the European Foundation for the Improvement of Living and Working Conditions Archived July 20, 2014, at the Wayback Machine

3. S. Terzi et al, Int. J. Product Lifecycle Management 4, No. 4, (2010)

4. G Pahl. et al. Engineering Design: A Systematic Approach (Elsevier P. House, 2007)

5. Standard EN 13306:2001 Terminologie de la maintenance, (2001)

6. North Atlantic Treaty Organization, Nato Standardization Agency (NSA) AAP-6Glossary of terms and definitions, p. 43

7. MIL--HDBK--2173 Department of Defense Handbook: Reliability-Centered Maintenance Requirements for Naval, Aircraft, Weapons systems and support equipment, (1998)

8. Standard BS EN 13460:2002 Maintenance-Documents for Maintenance, (2002)

9. K Takamura, KP Lok, R Wittlinger, Microsurfacing for preventive maintenance: ecoefficient strategy, Proceedings of the Forty-Seventh Annual Conference of the Canadian Technical Asphalt Association (CTAA): Calgary, Alberta, (2002)

10. P. Salling et al., Int. J. of LCA, 7(4), 203-218, DOI: 10.1007/BF02978875, (2002)

11. S. Takata, F. Kimura et.al. Maintenance: Changing Role in Life Cycle Management Annals of the CIRP, 53 (2) , 643-655, (2004)

12. S. Backlund, P. Thollander, M. Ottosson and J. Palm, Energy Policy (51), 392-396., (2012)

13. L. Chen J Cai, Reliab. Eng. Syst. Saf. 81/2, 147-154, https://doi.org/10.1016/S09518320(03)00075-9, (2003)

14. https://www.relyence.com/2019/07/24/guide-maintainability-prediction/, Accesed 15 february, 2020

15. L. M. Agudelo Gutierrez, Decision making support through the consideration of environmental criteria in preliminary design, ph. D. Thesis, (2016)

16. ISO / TR 14062: 2004 Environmental Management - Integrating Environmental Aspects Into Product Design and Development, (2004)

17. S. Anders S., Global Life Cycle Impact Assessments of Material Shifts: The Example of a Lead Free Electronics Industry, DOI 10.1007/978-1-84882-661-8, ISBN 978-184882-661-8, (2010) 